\title{
Implementation of Gamification from blended learning based on the flex model and efficacy of this program on students: an experiences from Iran, An Quasi-experimentaL Study
}

tahereh abdian ( $\sim$ tahere.abdian@gmail.com )

Jahrom University of Medical Science https://orcid.org/0000-0002-4333-4049

saeed abdollahifar

Shiraz University of Medical Sciences

Leili Mosalanejad

Jahrom University of Medical Science

Research article

Keywords: gamification, blended learning, flex model, students, education

Posted Date: September 19th, 2019

DOl: https://doi.org/10.21203/rs.2.14677/v1

License: (c) (i) This work is licensed under a Creative Commons Attribution 4.0 International License.

Read Full License 


\section{Abstract}

Background: New gamification technology with a detailed understanding of the goals and prospects, and with the help of game elements and techniques, leads to promotion of motivation and participation, and ultimately behavior change. Methods: In this study, with the design of mental illness lessons for undergraduate and executive groups, using flex model, two parts of technical and educational design were used. In the technical section, three parts on dynamics, mechanisms and elements of gaming were considered. Intervention was studied on different groups of medical students including medical, health, and laboratory sciences and its impact on learning and performance was studied using quantitative and qualitative analyses. Results: The results of the students' prospective about the efficacy of the method showed that the mean scores of most of the items were higher than the average. This implies that students' attitude towards using gamification was positive. In the other part, the qualitative results of the study were analyzed and the student's analysis of their advantages and disadvantages and their perceptions on the impact of the intervention were examined. Conclusion: Based on the Flex model, mental gamification based on blended learning is effective in shaping the students' satisfaction.

\section{Background}

Eighth art is the title these days is given to the art of the gaming industry. The game has taken a specific form at any time. In recent years, there have been many developments in the fields of science, art, industry and technology, numerous studies and new ideas being crystallized until the millennium saw the growth of computer and video games in many way [1]. Nowadays, computer games have found a lot of features and applications, and their prevalence in everyday life has made them out of pure fun and made gamemakers more than ever before use their capabilities in various educational, social, economic, political, and cultural fields [2]. Digital game-based learning is very close to game-based learning, with the distinction that it is related to digital games. For Prinsky, digital game-based learning is a "newer virtual learning process"[3]. The widespread use of new technologies such as the Internet, social networks and mobile phones are affecting the education process at the university. Technology has an important impact on education, enabling better communication and implementation of the latest information systems useful for learning and education [4].

\section{Game \& education}

Nowadays, game-based learning has become one of the hottest topics in education, and the user is influenced by an indirect education through the content, and narration of the game, without even realizing the norms and behaviors of the game characters themselves [5]. According to Curtis, game-based learning is generally about the influence of games on attracting and motivating users for a specific purpose, such as the development of knowledge and learning new skills [6].

Also, according to the Federation of American Scientists (2006), many of the features used in high quality learning environments are also found in video games, such as clear educational goals, ample opportunity to practice and enhance expertise, monitoring improvement, and compliance with the learner's mastery 
level [7]. Therefore, trying to serve games in non-game related arenas has led to the creation of a new concept and method called gamification [8] that can indirectly convey concepts, values and skills to an attractive space context; educate the audience; and expose them to unconscious learning [9].

\section{Gamification history}

New gamification technology with a detailed understanding of the goals and prospects, and with the help of game elements and techniques, promotes motivation and participation and ultimately behavior change [10]. Some have recognized its importance in the coming decade as being similar and equal to social networks and mobile. In 2012, a study was conducted by the Pew Research Center to predict the future of technology, media and cyberspace elites. Almost 53 percent of those surveyed believed their gamification would be ubiquitous in 2020. Another interesting finding, for example, was that 53 percent of those surveyed agreed that: "by 2020, there will be significant improvements in the use of gamification; and it will apply new ways in the areas of education, health, work and other aspects of human communication and will play an important role in the daily activities of many people who use communication networks in their daily lives [11].

\section{Gamification}

gamification technology is a tool for designing behaviors, and skills and enabling innovation. In combination with education and training, gamification can solve major challenges at the academic and educational level, such as motivation, interaction, and collaboration between students or learners to enhance their performance. To understand the potential of gamification, it is necessary to determine how to use these elements [12].

Some organizations today are skeptical about the viability and longevity of gamification as a means to engage and motivate the target audience, and people struggle to understand the trend and its longer-term implications. In a 2012 survey conducted by Pew Research Center, 53 percent of people surveyed said that by 2020 the use of gamification will be widespread, while 42 percent predicted that by 2020 gamification will not evolve to be a larger trend except in specific realms.

\section{Theoretical Background for Gamification}

The assessment step in phases one and two led to the following list of 11 theories

- Behavioral Decision Theory

- Behavioral Intention and Actual Behavior

- Cognitive Load Theory

- Elaboration Likelihood Model

- Flow Theory

- Homo Ludens

- Information Processing Theory 
- Keller's Motivational Model

- Organizational Learning Theory

- Self-Determination Theory

- Social Cognitive Theory and Social Learning Theory [13-15].

\section{Gamification elements}

Different design components for gamification of education are highlighted in these documents, along with their impact on the learners, which we referred to as learner in varied fields (Engagement, Satisfaction, enthusiasm, Enjoyment, Productive learning experience, Sense of accomplishment, Sense of achievement, Interest in course and presentation $[16,17]$.

\section{Blended learning}

The term 'blended learning' refers to the third generation of distance education systems. Combined learning is also called hybrid or blended learning, and there are generally many definitions of this term [18].

Blended learning is potentially more powerful than both traditional face to face learning and completely online learning. Blended learning, due to changes in teaching practices and the qualifications of teachers in schools, can help reduce the differences in success achievement. blended learning combines beneficial aspects of face to face learning with online learning in a balanced way which helps to get the maximum benefit of both learning environments' beneficial aspects of face to face learning with online learning[19].

\section{Blended learning models}

Blended learning means many things to many people, and blended-learning environment has six different models: face-to-face driver, rotation, flex, online lab, self-blend, and online driver[20].

Clayton Christensen's research on blended learning schools and programs found that the majority of blended programs fall into one of four models: Rotation, Flex, A La Carte, and/or Enriched Virtual[21].

As illustrated above, all blended learning models emphasize an existing convergence of both traditional and media-based learning environments to exploit the benefits of both approaches to make education more effective.

Blended learning has many benefits in educational programs. One of them is that utilizing technology extends the physical boundaries of the classroom, provides access to learning content and resources, and improves the ability of the educators to receive feedback on the learners' progress. Combined learning also offers multiple opportunities for communication, collaboration, interactions, and learning control[22]. 
Therefore, blended learning enables these multiple approaches to achieve the goals of the courses. Learners can progress on their own and even repeat parts of the curriculum [23].

\section{Benefits}

Increasing the retention and improvement of learning efficacy are other benefits of blended learning through empirical studies. Blended learning extends interaction between students and instructors through the use of email and asynchronous forums and enables the learners to learn. They have greater control over learning speed, educational flow, resource selection and time management, and are also effective in applying different learning styles [24].

Because teaching and learning are also an active process and, like any other process, there is a need for motivation at various stages in order to start and sustain it, nowadays one of the syndromes of learning environments is the problem of lack or scarcity of motivation in different educational levels. Boring learning environments shift the students from creativity and flourishing to obedience [25]. Therefore, given many benefits gamification offers to learners and the role it plays in enhancing the enjoyment and effectiveness of the learning process, it has become a popular approach in the education industry. The undeniable fact is that gamification success in the teaching and learning industry is due to its purely scientific principles[26].

Therefore, this study aimed to evaluate the implementation of a mental gamification from blended learning based on the flex model and efficacy of this program on students.

\section{Methods}

In this study with the design of mental illness lessons for undergraduate and executive groups using Flex model, two parts of technical and educational design were used.

In the technical design, the technical features and elements that are considered in the gamification will include the items outlined in the following image, which are considered in the nature of the various sections(Figure1). Study design and communication between all parts showed in (Figure 2 ).

\section{Design and development of gamification}

In the design of the tool, a list of educational necessities was first considered in the course, followed by various sections with basic sections on symptoms and symptoms of mental illness, followed by 11 sections on psychiatric disorders (psychotic, mood disorders, anxiety, descriptive, dissociative disorder, converting disorder , psycho - somatic, personality, and sexual) were designed and considered for drug and non-drug therapies.

Dimensions, questions and type of questions and elements 
Symptoms and symptoms of mental illness 40 ; multiple choice, matching

Psychiatric disorders 25 , multiple choice, matching cases

Mood disorders 23 , multiple choice, matching, cases

Anxiety disorder 32 , multiple choice, matching, cases

Psychosomatic disorder 25 , multiple choice, matching, cases

Dissociative disorder 27 , multiple choice, matching, cases

Converting disorder 27 , multiple choice, matching, cases

Sexual disorder 21 , multiple choice, matching, cases

Cognitive disorder 24, multiple choice, matching,, cases

Drug therapy 32 , multiple choice, matching, illustration

Psychosocial disorder 21, multiple choice, matching

Scenario writing in each section is different and various sections on multiple choice questions - drawing line - and working with simulated scenarios were considered to increase students' proficiency and enable them to gain deeper skills. In the design part, we tried to provide different elements to motivate and enhance the learning depth along with individual and collective learning.

\section{Gamification elements:}

In the scenario writing in the technical section, the three sections of dynamics, mechanisms and elements of gamification are taken into consideration. Dynamics include things like inter-departmental communication skills, upgrades, narrators of emotional situations, and limiters to keep the game dynamic. The Mechanism section addresses challenges, opportunities, competitions, collaborations, feedback, access to resources, rewards, segmentation, frequent rotations and rewarding situations, and key elements of the game such as using Avatars, models, sets, battles, increasing degrees of freedom, receiving gifts, leaderboards, dams, group comparison tables, team status, and virtual goods were used as elements.

\section{Participants}

Classes for mental health in specific part ( mental illness) was set from the period of march 2017 to June 2017 and august 2018 to September 2018.for medical, laboratory sciences \& public health students(75 people).

\section{Intervention}

The following steps were implemented in designing the gamification system:

1. Understanding the target audience : 
The author taught gamification for public health students in two semesters. The class was in three parts: lectures, seminar group discussion, blended learning by gamification in a flex model.

\section{Model}

The flex model is a method of teaching for students who are non-traditional learners. Learning material and instructions are given online and the lessons are self-guided. The teacher is available on-site. The students work independently and learn to develop and create new concepts in a digital environment [27].

Educational strategies by student center learning: blended learning by flex model.

One learning innovation that needs to be done to overcome these problems is by combining face-toface/conventional learning with e-learning and using the flipped classroom method or an inverse method where students get material through e-learning and face-to-face learning filled with practice or discussion[28].

To applied Flexed Model from blended learning

1-Define learning object

2- Concept presentation from lecture

3- Self blended by gamification

4- Ssmall group collaborative learning by gamification in class

5- Fallowing students by online LMS and task

6- Evaluation of the students' activities

Evaluation was done about the students' satisfaction by open ended questions in the final exam. And then main rephrased themes were extracted. Also, gamification effectiveness of was assessed by a questionnaire. The data were collected through a questionnaire with 23 items in 5 continuum for the evaluation of students' satisfaction $(\mathrm{N}=32)$. This questionnaire was validated by translation-retranslation and applied on 20 students (The validity of the questionnaire was measured based on the content validity using the experts' views. Furthermore, the reliability of the questionnaire was confirmed using correlation coefficient of $0.74[29,30]$. Also we used E Game Flow qustionnire (scale to measure learners' enjoyment of e-learning games) [31].This questionnaire with 42 items in 5 continuum and 8 dimensions constructed.

This dimensions conclude (Concentration (8), Goal Clarity(5) ,Feedback (6),Challenge (11),Autonomy (9) ,Immersion (7),Social Interaction (6),Knowledge Improvement(5). This questionnaire was validated by translation-retranslation and applied on 20 students (The validity of the questionnaire was measured 
based on the content validity using the experts' views. Furthermore, the reliability of the questionnaire was confirmed using correlation coefficient of 0.83

\section{Results}

In the two classes, 30 participants were female and the remainder was male. All the participants were public health sciences students in two groups. The result from students' prospective about the efficacy of the method showed that the mean scores of most of the items were higher than the average. This implies that the students' attitude towards using gamification was positive.

The high mean score of Perceived Usefulness, Perceived Ease of Use, Attitude, Skill Engagement and Interaction Engagement list is shown in Table 1.

In the other part, the qualitative results of the study were analyzed and the student's analysis of their advantages and disadvantages and their perceptions of the impact of the intervention were examined. The extracted themes included the following items (Table 2).

Another results showed that game flow of gamification intervention . this result state the high average percentage of dimensions using intervention( Table 3).

\section{Discussion}

The importance of teaching-learning and the increasing demand for access to education on the one hand, and emphasizing the effectiveness of education, while reducing its costs, on the other, is one of the challenges to which all educational organizations are faced.

The results of this study showed that students tended to use gamification if it was easy to access and use, as well as agreeing that it was useful in their learning. Also in analyzing the qualitative results of the study, the students expressed their advantages and disadvantages and feelings about the impact of gamification.

The results of the analysis of the findings of this study show that the efficiency and effectiveness of mental gamification is high. Based on the mean and standard deviation obtained in terms of student usefulness, they strongly agree with the usefulness of mental gamification, indicating that all students agreed that using classroom gamification technology could be effective in their learning.

Several elements have been used in gamification design that has been used in numerous studies and the positive effects of each of the different dimensions have been discussed in the studies. In this study, motivational elements were used in gamification design and it was found that these components had a positive impact on motivation and positive attitude of users and had a positive effect on learning indicators. Much evidence supports this and emphasizes its impact [32-36]. 
The impact of play on learning, performance, motivation, and satisfaction has also been emphasized in many studies. These data corroborate the qualitative and quantitative findings of the present study [3741]. The impact of play on motivation as an important and influencing factor on learning has been confirmed in many studies [42, 43]. And some also emphasize its impact on performance[44, 45].

Lee and Hammer's (2011) study has shown that gamification can be effective in the students' learning and enhances the learners' problem-solving skills in a complex format that encourages the learners to explore the problem. In a study by Wang and Lieberoth (2016) that examined the effect of attention and noise on focus, interaction, enjoyment, learning, motivation, and classroom dynamics using the Kahootbased learning platform on 593 students, the results revealed that the use of the Kahoot-based learning platform had a positive effect on classroom dynamics, learning interaction, and student's motivation[46]. Therefore, the results of this study are in line with the present study and show that gamification can be effective in teaching and learning.

Also, the mean and standard deviation of the "ease of use" score was 2 to 4 , indicating that generally, the students agree with the ease of use of gamification technology in this study, which is in line with Rahman's (2018) study results. In this study, the results showed that students in particular tended to engage in activities that were easier to use the platform than the benefits they could derive from the product. It was concluded that Perceived Ease of Use Items (PEOU) was a better indicator of the students' attitude toward gamification [30].

In the field of attitude, the results also showed that students had a positive attitude toward mental gamification. A study by Cheong (2014) that examined the students' perceptions of game elements showed that all elements of the game presented to respondents were highly rated. And it was found that undergraduate students had a positive understanding of the systems that used game elements and were interested in using them for learning [47], which is consistent with the results of the present study.

In the area of interaction and participation and the use of skills, the results also indicated that mental gamification was effective in the students' interaction in the classroom, and research has shown that game elements may actually increase the levels of intrinsic motivation[48]. In a study by Seixas et al. (2016) that examined the effectiveness of gamification on student engagement, tit was found that gamification had a positive effect on student interaction [49], which is consistent with the results of this study and both confirm the effectiveness of gymnastics on the amount of learner interaction in the classroom. Also, a review study by Faiella et al. (2015) showed that the use of game elements must be used correctly and appropriately, strategically and appropriately in order to create a high level of active participation and motivation, which also motivates learning. In turn, it can produce positive results in cognitive, emotional, and social domains[50].

Atmacasoy and Aksu (2018) in their review study of Turkish universities found that blended learning had a positive effect on the students' motivation and success, which is consistent with the present study [51]. 
Also, according to the second part of the study, an interview with the students based on the extracted themes, such as enhancing the students' learning and retention and its depth, showed different effects of blended learning based on play versus traditional methods.

Creating healthy group and individual competition among students was another theme extracted from the interviews of the students participating in the present study. They have been effective in their learning and academic motivation.

In their study, Meng Tan and Khe Foon Hew (2016) also examined the interaction, affect, and emotional outcomes of 22 students using blended learning and the incorporation of meaningful gamification into their learning. There was an increase in the students' participation in discussion communities, but it did not have a significant impact on the students' actual learning on the subject.

Although there was no significant statistical evidence to support the increase in student post-test scores, the participants' performance quality in the experimental group was generally higher than in the control group. It also showed that using game mechanics had a positive impact on students' motivation to engage in more challenging activities during the course. In the present study, mental gamification also influenced thestudents' interaction in the classroom [52].

Studies have shown that in blended learning, in the form of gamification, in which students are in the learning + gamification group often explain their views on the topic in the classroom better than other students who receive simple instruction [53].

As mentioned earlier, the teacher found that students in the blended learning + gamification group mostly explained their own opinions about the topic rather than challenging other people's views.

Since games can have multiple functions, such as learning, recreation, helping to explore new skills, increasing self-esteem, practicing skills and changing attitudes, the use of gamification is of tremendous value in education [54]. Thus, the results of this study suggest that the structure of students' interaction can be a measure of their acceptance of the use of gamification. However, perceived ease of use, usefulness, and perceived attitudes toward using gamification technology structures should generally be taken into account in the student participation orientation to be able to attract the learners to enhance the student engagement and interaction in the classroom. One of the limitations of this study was the shortage of samples of two groups of students in two consecutive years. However, taking advantage of it at the level of group in the learning environment provided the opportunity to interact and explore dynamic classroom processes.

\section{Conclusions}

The results indicated the positive effects of this intervention on learning and their satisfaction indices. It is necessary to examine the use of this method in different groups and units in order to use and develop 
the positive effects of technology on education. Using the theory of constructivism, this approach can make an important contribution to the construction of knowledge and active, student-centered learning.

\section{Declarations}

\section{Acknowledgments}

The authors wish to thank the Jahrom Deputy research for support this article. Additionally, thank you to all participants in the study for assist with this research project.

\section{Authors Contributions}

All authors listed have contributed sufficiently to the project.

Study design: LM, SA. Database search, data extraction and evaluation: LM and TA. Writing original draft: LM, SA, and TA. Review and editing: LM, SA, TA. All authors have read and approved the final version of the manuscipt.

\section{Funding}

Not applicable.

\section{Availability of data and materials}

The data that support the findings of this study are available from the corresponding author on request.

\section{Ethics approval and consent to participate}

Permission to conduct this study has been received from the Jahrom University of Medical Sciences. Ethics Committee with IR.JUMS.REC.1396.002 ethical cod. The Consent obtained from study participants was written.

\section{Consent for publication}

Not applicable.

\section{Competing interests}

The authors declare that they have no competing interests.

\section{Author details}

${ }^{1}$ Medical Education Department, Jahrom University of Medical Sciences, Jahrom 0957, Iran. ${ }^{2}$ Medical student, Student Research committed, Shiraz University of Medical Sciences, Shiraz 7675 , Iran. ${ }^{3}$ Nursing Department, Jahrom University of Medical Sciences, Jahrom 4049, Iran 


\section{References}

1. Novak J, and L Levy, Play the game: the parent's guide to video games. 2008: Cengage Learning.

2. Mochocki M, Reality is Broken: Why Games Make Us Better and How They Can Change the World. Jane McGonigal. 2011. New York: Penguin Press, ss. 388. Czasopismo ludologiczne Polskiego Towarzystwa Badania Gier. 2011; 239.

3. Prensky M, Digital game-based learning. Computers in Entertainment (CIE).2003; 1(1): 21-21.

4. Urh MG. Vukovic, and E. Jereb, The model for introduction of gamification into e-learning in higher education. Procedia-Social and Behavioral Sciences. 2015; 197: 388-397.

5. Perrotta C, et al., Game-based learning: Latest evidence and future directions. NFER Research Programme: Innovation in Education. Slough: NFER. 2013; 1-49.

6. Corti K. Games-based Learning; a serious business application. Informe de PixelLearning. 2006; 34(6):1-20.

7. Scientists FoA. Summit on Educational Games: Harnessing the Power of Video Games for Learning., in The Learning Federation. 2006, Washington, DC.

8. Kapp KM. The gamification of learning and instruction fieldbook: Ideas into practice. 2013: John Wiley \& Sons.

9. Landers RN. Developing a theory of gamified learning: Linking serious games and gamification of learning. Simulation \& gaming. 2014;45(6): 752-768.

10. Deterding S. Gamification: designing for motivation. interactions, 2012;19(4): 14-17.

11. Bruke B. Gamify: How gamification motivates people to do extraordinary things. 2016

12. Landers RN. and A.K. Landers, An empirical test of the theory of gamified learning: The effect of leaderboards on time-on-task and academic performance. Simulation \& Gaming. 2014; 45(6): 769785.

13. Putz, LM. and H. Treiblmaier, Creating a theory-based research agenda for gamification. 2015.

14. Robson K., et al., Is it all a game? Understanding the principles of gamification. Business Horizons. 2015; 58(4): 411-420.

15. Ruhi, U., Level up your strategy: Towards a descriptive framework for meaningful enterprise gamification. Technology Innovation Management Review. 2015.

16. Betts, BWJ. Bal, and A.W. Betts, Gamification as a tool for increasing the depth of student understanding using a collaborative e-learning environment. International Journal of Continuing Engineering Education and Life Long Learning. 2013; 23(3-4): 213-228.

17. Nah, FFH., et al. Gamification of education using computer games. in International Conference on Human Interface and the Management of Information. 2013. Springer.

18. Moskal PC. Dziuban, and J. Hartman, Blended learning: A dangerous idea? The Internet and Higher Education. 2013, 18: 15-23. 
19. Saritepeci, M. and H. Cakir, The effect of blended learning environments on student motivation and student engagement: A study on social studies course. Egitim ve Bilim, 2015; 40(177).

20. Tolley B. Creating successful blendedlearning classrooms, 2014.

21. Powell A., et al., Blending Learning: The Evolution of Online and Face-to-Face Education from 20082015. Promising Practices in Blended and Online Learning Series. International association for K-12 online learning. 2015.

22. Farrell GF. Using a blended learning model to facilitate personalization of reading instruction for primary students. 2018.

23. Holley D. and M. Oliver, Student engagement and blended learning: Portraits of risk. Computers \& Education, 2010;54(3): 693-700.

24. Rossett, A. and R.V. Frazee, Blended learning opportunities. New York, NY. American Management Association, 2006.

25. Council, N.R., A framework for K-12 science education: Practices, crosscutting concepts, and core ideas. 2012: National Academies Press.

26. Dicheva, D., et al., Gamification in education: A systematic mapping study. Educational Technology \& Society. 2015; 18(3): 75-88.

27. Bailey J., et al., Blended learning implementation guide 2.0. DIGITAL SHIFT, 2013.

28. Graham, C.R., C.R. Henrie, and A.S. Gibbons, Developing models and theory for blended learning research. Blended learning: Research perspectives, 2014; 2: 13-33.

29. Mosalanejad I A.s., Gamification in Psychiatry: Design and Development of Native Model and the Innovate Strategy in Medical Education as a Funny and Exciting Learning. P J M H S. 2018; 12(4).

30. Rahman, R.A., S. Ahmad, and U.R. Hashim, The effectiveness of gamification technique for higher education students engagement in polytechnic Muadzam Shah Pahang, Malaysia. International Journal of Educational Technology in Higher Education, 2018; 15(1): 41.

31. Fu FL, RC. Su, and SC. Yu, EGameFlow: A scale to measure learners' enjoyment of e-learning games. Computers \& Education. 2009; 52(1): 101-112.

32. Denny, P. The effect of virtual achievements on student engagement. in Proceedings of the SIGCHI conference on human factors in computing systems. 2013. ACM.

33. DomíNguez, A., et al., Gamifying learning experiences: Practical implications and outcomes. Computers \& Education. 2013; 63:380-392.

34. Guin, TDL., et al., Myths and realities of respondent engagement in online surveys. International Journal of Market Research. 2012; 54(5): 613-633.

35. Gustafsson, A., C. Katzeff, and M. Bang, Evaluation of a pervasive game for domestic energy engagement among teenagers. Computers in Entertainment (CIE). 2009;7(4): 54.

36. Hamari J., Transforming homo economicus into homo ludens: A field experiment on gamification in a utilitarian peer-to-peer trading service. Electronic commerce research and applications. 2013;12(4): 236-245. 
37. Berns A., et al., Motivation, students' needs and learning outcomes: A hybrid game-based app for enhanced language learning. SpringerPlus. 2016; 5(1):1305.

38. Ibanez MB, ADi-Serio, and C. Delgado-Kloos, Gamification for engaging computer science students in learning activities: A case study. IEEE Transactions on learning technologies, 2014; 7(3): 291-301.

39. Knautz K., et al. From know that to know how-Providing new learning strategies for information literacy instruction. in European Conference on Information Literacy. 2014. Springer.

40. Mosalanejad L., B. Razeghi, and S.A. Ifard, Educational Game: A Fun and team based learning in psychiatric course and its effects on Learning Indicators. Bangladesh Journal of Medical Science. 2018; 17(4): 631-637.

41. Panagiotis F., et al., Climbing up the leaderboard: An empirical study of applying gamification techniques to a computer programming class. Electronic Journal of e-learning. 2016; 14(2): 94-110.

42. Harms J., et al. Low-cost gamification of online surveys: Improving the user experience through achievement badges. in Proceedings of the 2015 Annual Symposium on Computer-Human Interaction in Play. 2015. ACM.

43. Morschheuser B., C. Henzi, and R. Alt. Increasing Intranet Usage through Gamification--Insights from an Experiment in the Banking Industry. in 2015 48th Hawaii International Conference on System Sciences. 2015. IEEE.

44. Juźwin M., et al. Threats of using gamification for motivating web page quality evaluation. in Proceedings of the 2014 mulitmedia, interaction, design and innovation international conference on multimedia, interaction, design and innovation. 2014. ACM.

45. Krause, M., et al. A playful game changer: Fostering student retention in online education with social gamification. in Proceedings of the Second (2015) ACM Conference on Learning@ Scale. 2015. ACM.

46. Wang A.I. and A. Lieberoth. The effect of points and audio on concentration, engagement, enjoyment, learning, motivation, and classroom dynamics using Kahoot. in European Conference on Games Based Learning. 2016. Academic Conferences International Limited.

47. Cheong C., J. Filippou, and F. Cheong, Towards the gamification of learning: Investigating student perceptions of game elements. Journal of Information Systems Education, 2014; 25(3).

48. Sailer M., et al., How gamification motivates: An experimental study of the effects of specific game design elements on psychological need satisfaction. Computers in Human Behavior. 2017. 69: 371380.

49. da Rocha Seixas, L., A.S. Gomes, and I.J. de Melo Filho, Effectiveness of gamification in the engagement of students. Computers in Human Behavior. 2016. 58: p. 48-63.

50. Faiella F. and M. Ricciardi, Gamification and learning: a review of issues and research. Journal of eLearning and Knowledge Society. 2015. 11(3).

51. Atmacasoy, A. and M. Aksu, Blended learning at pre-service teacher education in Turkey: A systematic review. Education and Information Technologies. 2018; 23(6): 2399-2422. 
52. Tan, M. and K.F. Hew, Incorporating meaningful gamification in a blended learning research methods class: Examining student learning, engagement, and affective outcomes. Australasian Journal of Educational Technology. 2016; 32(5).

53. Lam YW, K, Hew, and KF. Chiu, Improving argumentative writing: Effects of a blended learning approach and gamification. Language learning \& technology, 2018.

54. Fan KK, Pw. Xiao, and CH. Su. The Effects of Learning Styles and Meaningful Learning on the Learning Achievement of Gamification Health Education Curriculum. Eurasia Journal of Mathematics, Science \& Technology Education. 2015; 11(5).

\section{Tables}

Table 1: Effect of gamification on students' engagement $(n=75)$ 
Perceived Usefulness Items (PU)/Measurement
Using the online gamification system improves my learning performance
3.47
0.91
0.32
Using the online gamification system increases my learning outcome
3.72
0.83

0.14

Using the online gamification system enhances my desire to produce desired result in my learning

\section{$3.94 \quad 1.36 \quad 0.17$}

Using the online gamification system is useful in my learning

0.18

Perceived Ease of Use Items (PEOU)/Measurement(

I find the online gamification system to be flexible to be used

3.79

0.34

0.16

The online gamification functionality and interface is clear and understandable 4.63

1.52

0.32

Interacting with the online gamification system does not require

2.38

1.65

0.25

a lot of my mental effort

Overall, I believe that the online gamification system is easy to use

4.23

0.64 0.19

Attitude (A)/Measurement(

I think that using online gamification system is a good idea

4.13

$1.23 \quad 0.22$

I like learning with online gamification system

3.78

1.64

0.24

I look forward to those aspects of my learning that require the use of online gamification system

$\begin{array}{lll}3.72 & 1.34 & 0.43\end{array}$

Skill Engagement (SKE)/Measurement Online gamification system encourage me in:

Taking good notes in classroom

$\begin{array}{lll}3.09 & 1.28 & 0.32\end{array}$

Listening carefully in classroom

$\begin{array}{lll}4.81 & 1.20 & 0.17\end{array}$

Making sure to study on regular basis

$3.36 \quad 1.23$

0.15

Interaction Engagement (IE)/Measurement gamification system contribute to me in:

Having fun in the classroom

4.13

$0.62 \quad 0.04$

Participating actively in small-group discussions

$3.23 \quad 1.13$

0.22

Helping fellow students

Asking questions when I did not understand the lecturer

$3.69 \quad 1.24$

0.33

$\begin{array}{lll}3.92 & 0.55 & 0.34\end{array}$

Table 2 : paraphrasing students opinion about gamification in education 
- Creating a fun and motivating environment for learning

- Creating healthy group and individual competition among students

- Increasing and deepening the students' learning and retention

- Requiring careful study in answering the questions

- Being different from traditional education

- Fun and effective technology in the classroom

- Good sense of power and mastery of learning contents

- The difficult, yet being challenging and fun, nature of learning

- Not getting tired of learning and learning from mistakes

- Relationship between theoretical and practical content and link to the past comprehensive experiences

- Learning from the misconceptions of knowledge in understanding

\section{Weak points}

The difficulty of the questions and the need to fully master the learning content

The need for a thorough and in-depth understanding of course content

Necessity of time management in solving questions

Not taking some members of the group seriously

Table 3 : Game flow from students' opinion 


\section{Concentration}

C1 The game grabs my attention

C2 The game provides content that stimulates my attention

C3 Most of the gaming activities are related to the learning task

C4 No distraction from the task is highlighted

C5 Generally speaking, I can remain concentrated in the game

C6 I am not distracted from tasks that the player should concentrate on

C7 I am not burdened with tasks that seem unrelated

$19(63 / 33) \quad 11(36 / 67)$

$20(66 / 67) \quad 10(33 / 33)$

C8 Workload in the game is adequate

\section{Goal Clarity}

G1 Overall game goals were presented in the beginning of the game

21(70) $\quad 9(30)$

18(60) 12(40)

$22(73 / 33) \quad 8(26 / 67)$

18(60) 12(40)

24(80) 6(20)

21(70) $9(30)$

G2 Overall game goals were presented clearly

G3 Intermediate goals were presented in the beginning of each scene

G4 Intermediate goals were presented clearly

G5 I understand the learning goals through the game

\begin{tabular}{cc}
$20(66 / 67)$ & $10(33 / 33)$ \\
$20(66 / 67)$ & $10(33 / 33)$ \\
$18(60)$ & $12(40)$ \\
$21(70)$ & $9(30)$ \\
$25(83 / 33)$ & $5(16 / 67)$ \\
\hline
\end{tabular}

\section{Feedback}

F1 I receive feedback on my progress in the game

F2 I receive immediate feedback on my actions

$19(63 / 33) \quad 11(36 / 67)$

F3 I am notified of new tasks immediately

F4 I am notified of new events immediately

$25(83 / 33) \quad 5(16 / 67)$

F5 I receive information on my success (or failure) of intermediate goals immediately

$24(80)$

$6(20)$

F6 I receive information on my status, such as score or level

$21(70)$

$9(30)$

\section{Challenge}

H1 I enjoy the game without feeling bored or anxious

H2 The challenge is adequate, neither too difficult nor too easy

H3 The game provides "hints" in text that help me overcome the challenges

H4 The game provides "online support" that helps me overcome the challenges

H5 The game provides video or audio auxiliaries that help me overcome the challenges

H6 My skill gradually improves through the course of overcoming the challenges

H7 I am encouraged by the improvement of my skillsa

H8 The difficulty of challenges increase as my skills improved.

H9 The game provides new challenges with an appropriate pacing

H10 The game provides different levels of challenges that tailor to different players

\section{Autonomy}

A1 I feel a sense of control the menu (such as start, stop, save, etc.)a

A2 I feel a sense of control over actions of roles or objectsa

A3 I feel a sense of control over interactions between roles or objectsa

A4 The game does not allow players to make errors to a degree that they cannot

progress in the gamea

A5 The game supports my recovery from errorsa

A6 I feel that I can use strategies freelya

A7 I feel a sense of control and impact over the game

A8 I know next step in the game

A9 I feel a sense of control over the game

\section{Immersion}

I1 I forget about time passing while playing the game

20(66/67) 10(33/33)

$\begin{array}{cc}23(76 / 67) & 7(23 / 33) \\ 22(73 / 33) & 8(26 / 67) \\ 25(83 / 33) & 5(16 / 67) \\ 23(76 / 67) & 7(23 / 33) \\ 18(60) & 12(40)\end{array}$

21(70) 9(30)

$19(63 / 33) \quad 11(36 / 67)$

$23(76 / 67) \quad 7(23 / 33)$

$20(66 / 67) \quad 10(33 / 33)$

$22(73 / 33) \quad 8(26 / 67)$

$\begin{array}{cc}24(80) & 6(20) \\ 19(63 / 33) & 11(36 / 67) \\ 18(60) & 12(40) \\ 23(76 / 67) & 7(23 / 33)\end{array}$

\begin{tabular}{cc}
$24(80)$ & $6(20)$ \\
$19(63 / 33)$ & $11(36 / 67)$ \\
$21(70)$ & $9(30)$ \\
$24(80)$ & $6(20)$ \\
$25(83 / 33)$ & $5(16 / 67)$ \\
\hline
\end{tabular}

$20(66 / 67) \quad 10(33 / 33)$ 
I2 I become unaware of my surroundings while playing the game

I3 I temporarily forget worries about everyday life while playing the game

I4 I experience an altered sense of time

I5 I can become involved in the game

I6 I feel emotionally involved in the game

I7 I feel viscerally involved in the game

\section{Social Interaction}

S1 I feel cooperative toward other classmates

S2 I strongly collaborate with other classmates

S3 The cooperation in the game is helpful to the learning

S4 The game supports social interaction between players (chat, etc)

S5 The game supports communities within the game

S6 The game supports communities outside the game

\section{Knowledge Improvement}

K1 The game increases my knowledge

K2 I catch the basic ideas of the knowledge taught

K3 I try to apply the knowledge in the game

K4 The game motivates the player to integrate the knowledge taught

K5 I want to know more about the knowledge taught

\begin{tabular}{cc}
$22(73 / 33)$ & $8(26 / 67)$ \\
$23(76 / 67)$ & $7(23 / 33)$ \\
$23(76 / 67)$ & $7(23 / 33)$ \\
$20(66 / 67)$ & $10(33 / 33)$ \\
$22(73 / 33)$ & $8(26 / 67)$ \\
$22(73 / 33)$ & $8(26 / 67)$ \\
\hline
\end{tabular}

\begin{tabular}{cc}
$24(80)$ & $6(20)$ \\
$25(83 / 33)$ & $5(16 / 67)$ \\
$23(76 / 67)$ & $7(23 / 33)$ \\
$24(80)$ & $6(20)$ \\
$21(70)$ & $9(30)$ \\
$24(80)$ & $6(20)$ \\
\hline
\end{tabular}

$\begin{array}{cc}25(83 / 33) & 5(16 / 67) \\ 18(60) & 12(40) \\ 22(73 / 33) & 8(26 / 67) \\ 18(60) & 12(40) \\ 19(63 / 33) & 11(36 / 67)\end{array}$

\section{Figures}
1. Challenges
2. Chance
1. Constraints
2. Emotions
3. Narrative
3. Competition
4. Progression
4. Cooperation
5. Relationships
5. Feedback

6. Resource Acquisition

7. Rewards

8. Transactions

9. Turns

10. Win states
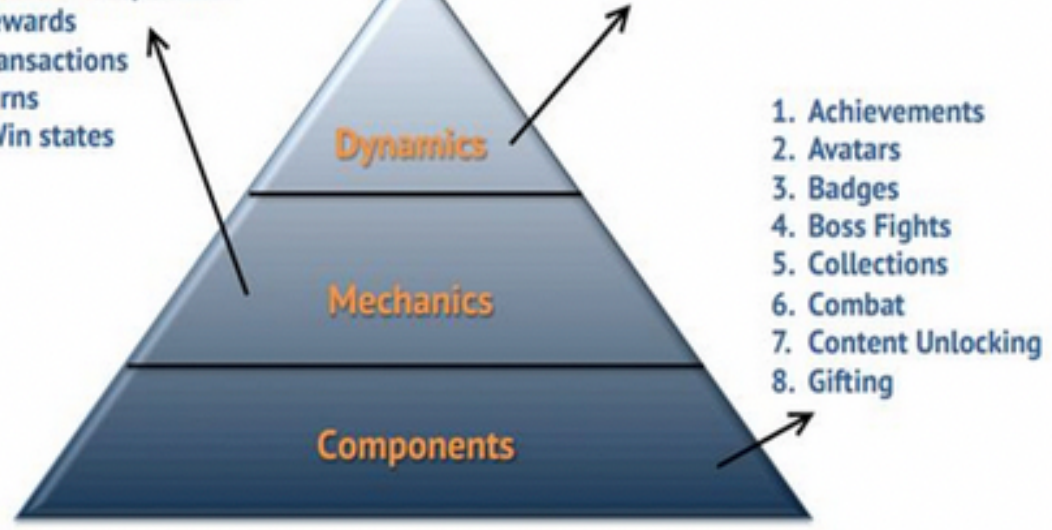

1. Achievements

2. Avatars

7. Content Unlocking

8. Gifting
9. Leaderboards

10. Levels

11. Points

12. Quests

13. Social Graph

14. Teams

15. Virtual goods 


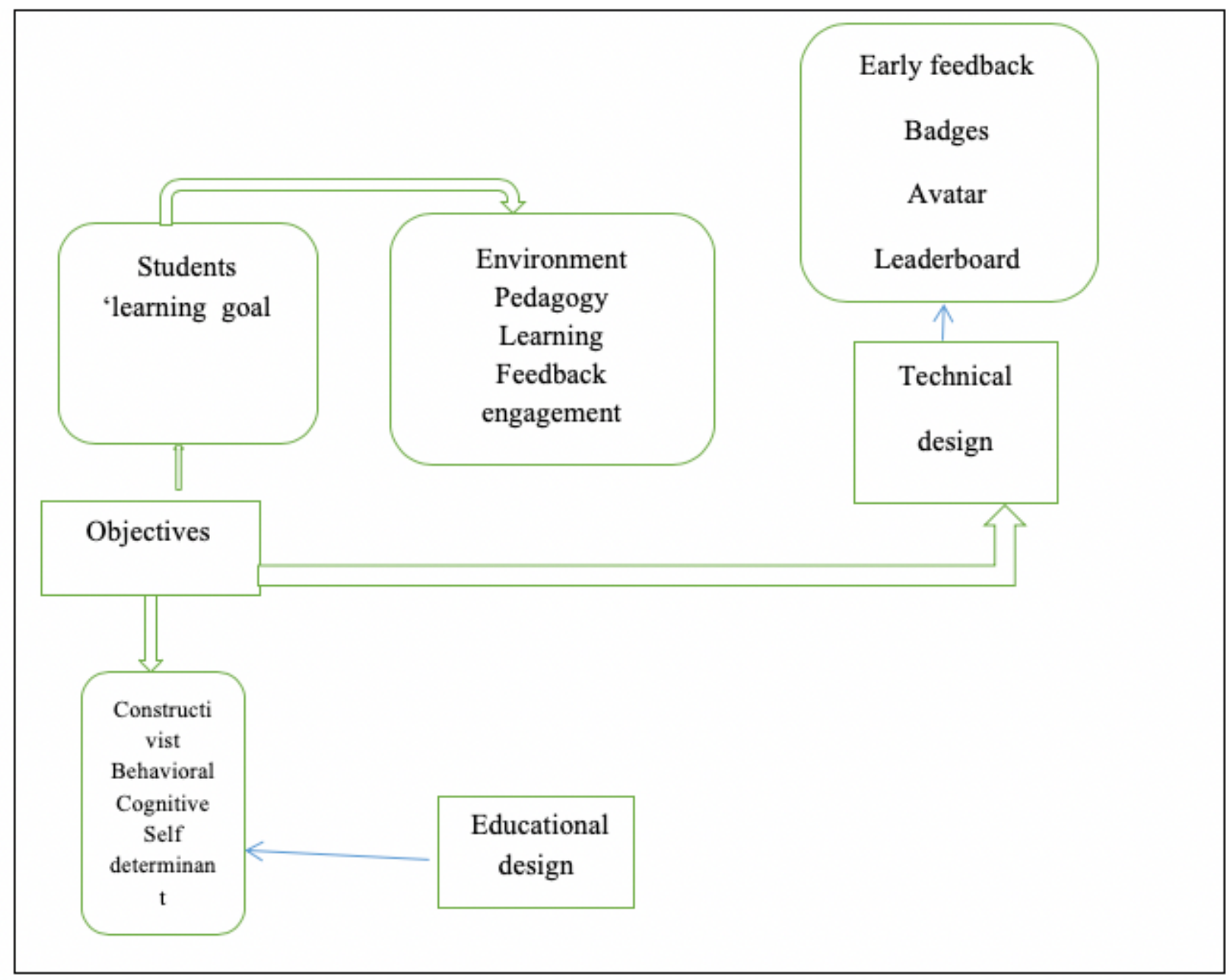

\section{Figure 2}

study design in gamification

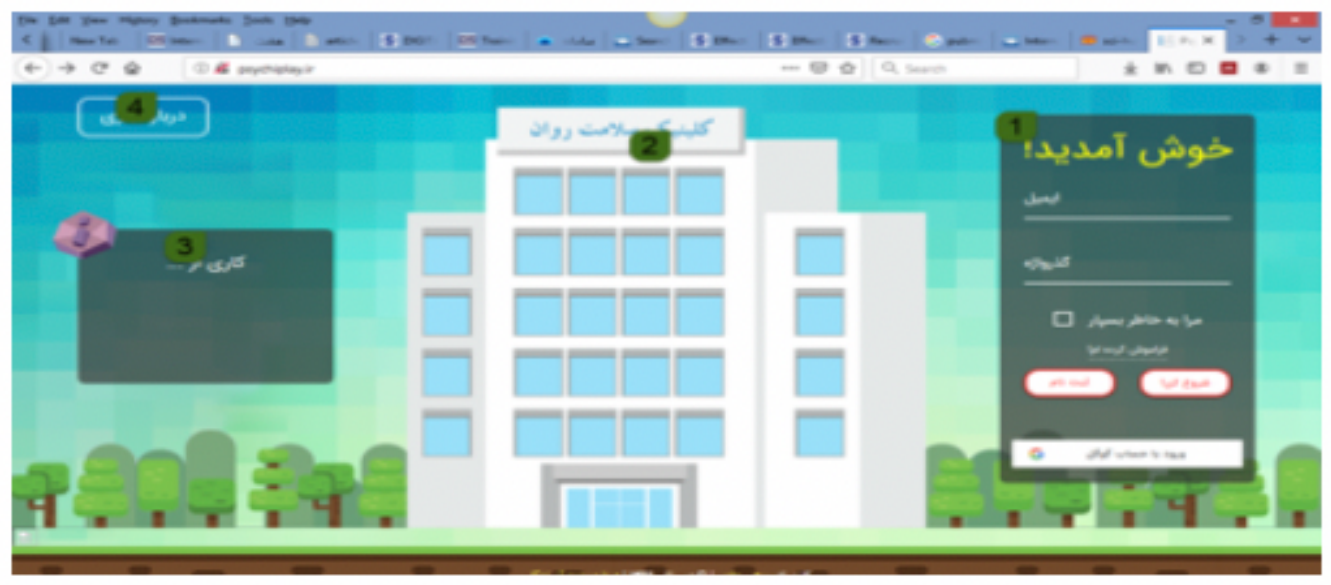

Figure 3 
1:Registration; 2:main questions ;3:publisher;4: about us

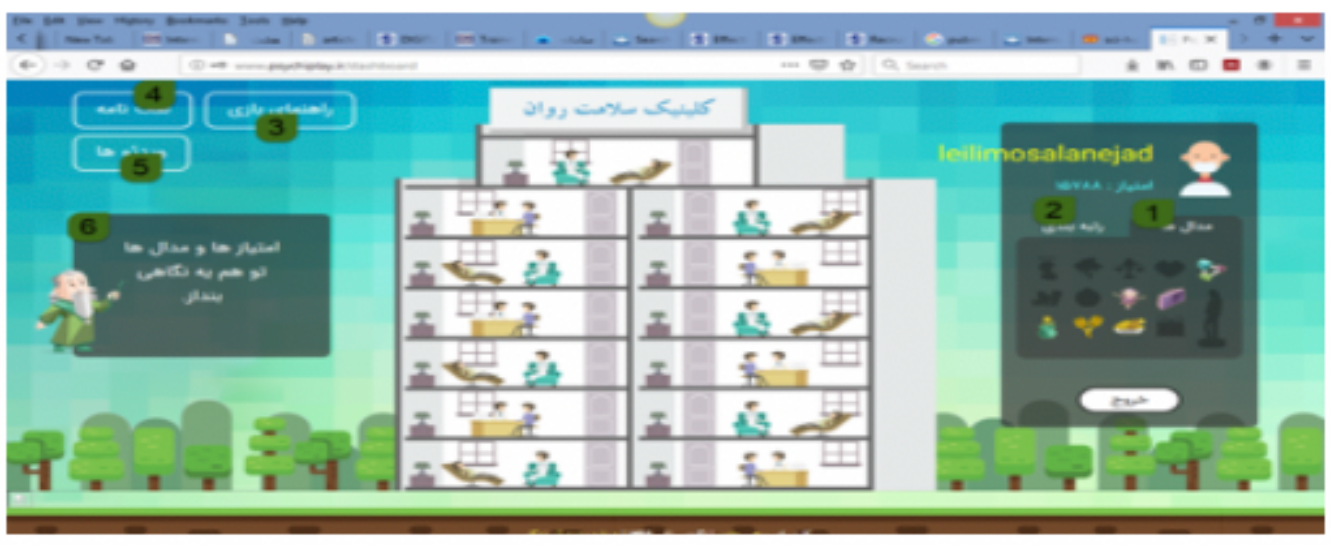

\section{Figure 4}

1:badges;2: leaderboard;3:direction ;4:glossary;5: video for reward

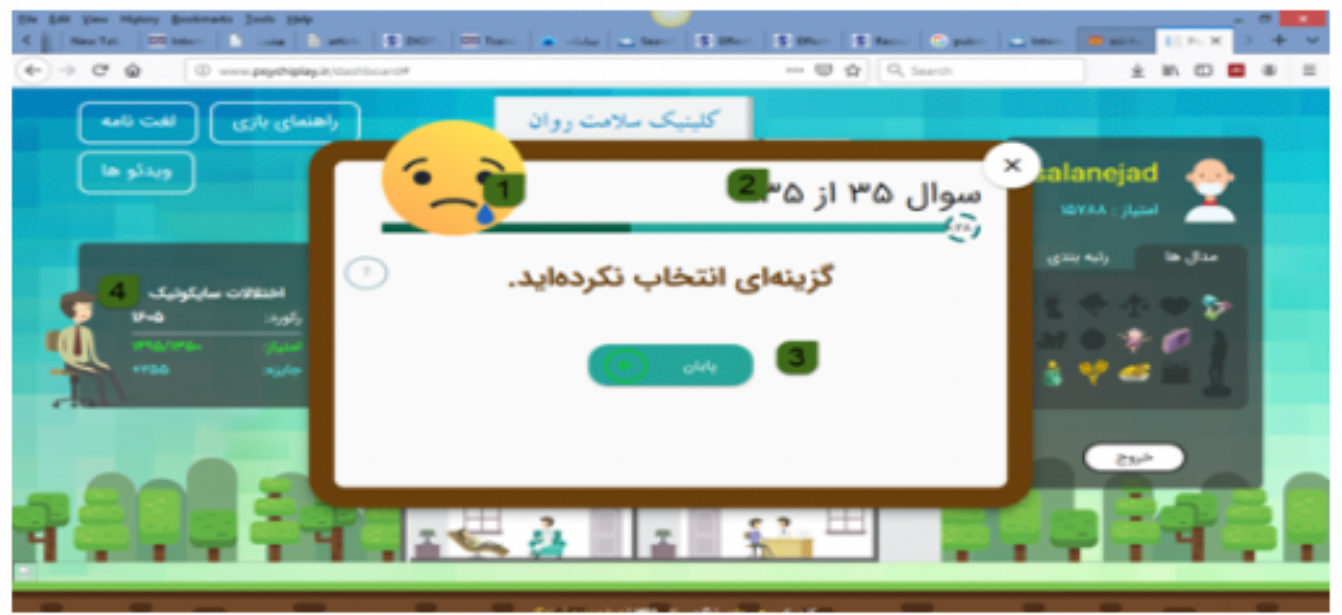

Figure 5

1:feed back;questions' number;3:items;4: status and level 


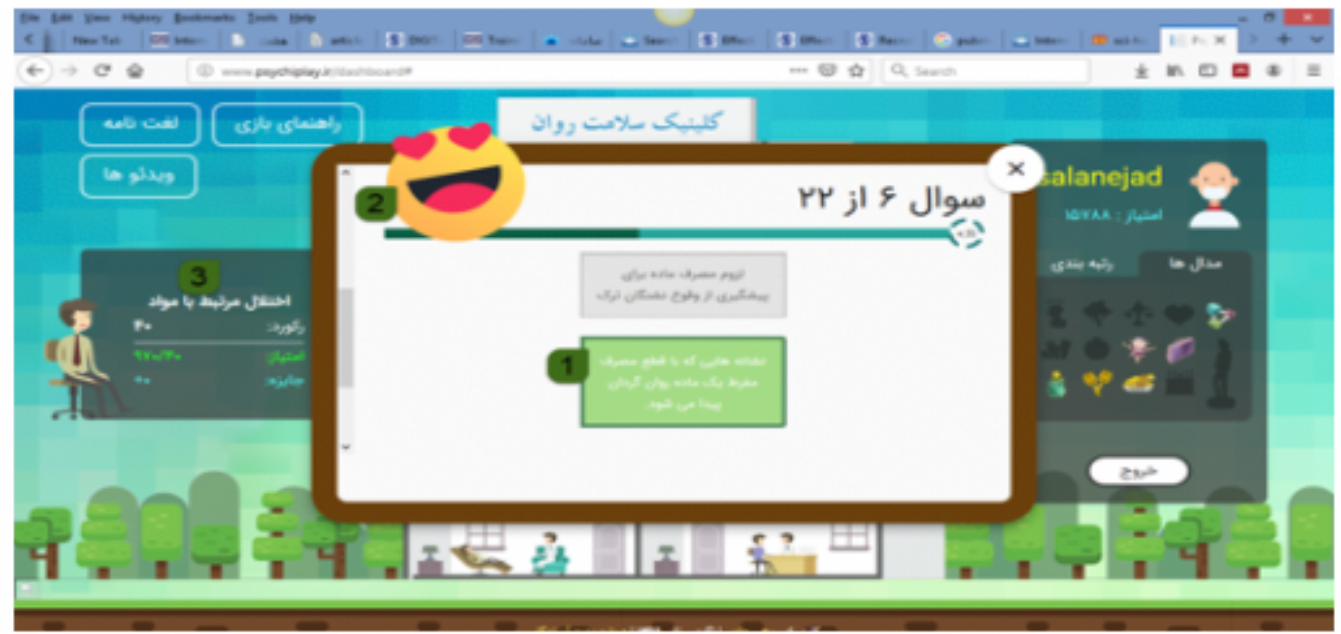

\section{Figure 6}

1:items ;2: feedback;3:status and level

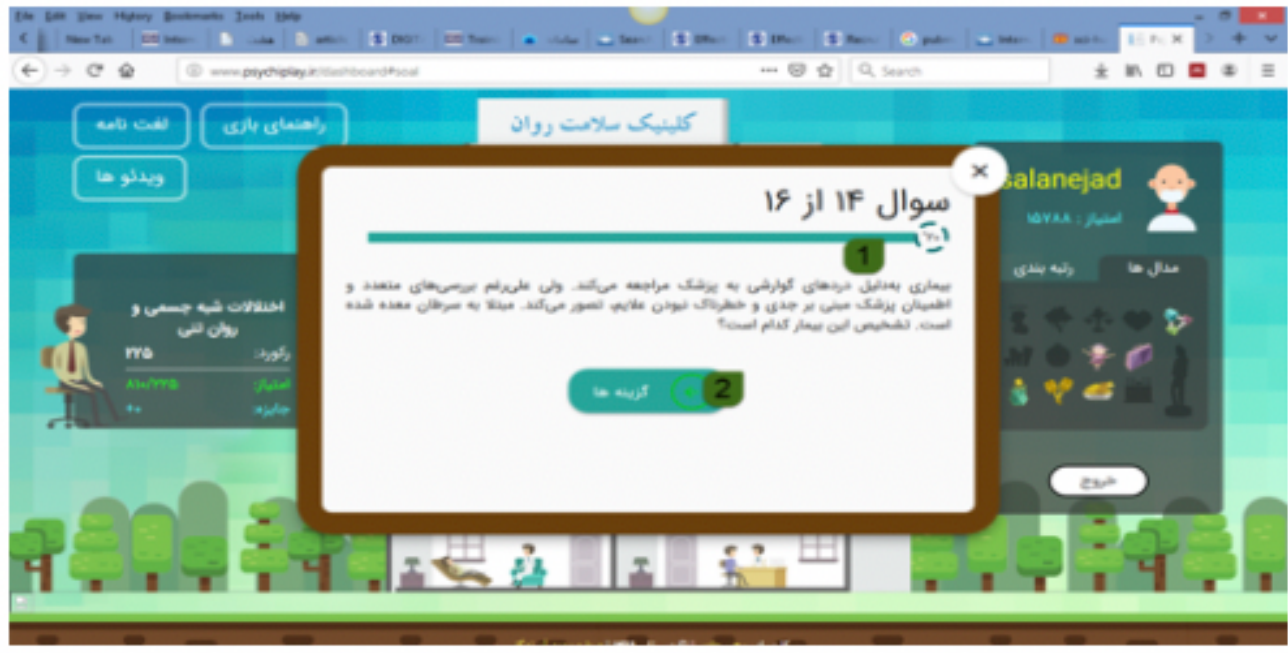

Figure 7

1:case question;2: items 


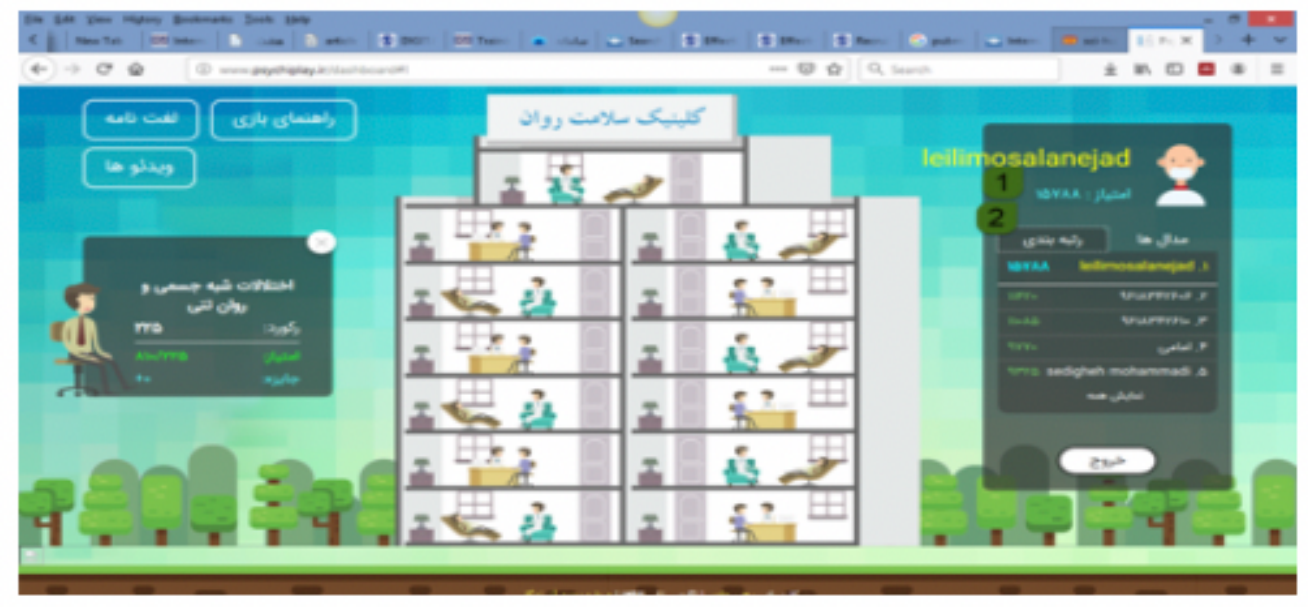

Figure 8

1 leaderboard; 2: badges 